Research Article

\title{
The Elevation of LC-ESI-Q-TOF-MS Response in the Analysis of Isoquinoline Alkaloids from Some Papaveraceae and Berberidaceae Representatives
}

\author{
Wirginia Kukula-Koch \\ Chair and Department of Pharmacognosy with Medicinal Plants Unit, 1 Chodzki St., 20-093 Lublin, Poland \\ Correspondence should be addressed to Wirginia Kukula-Koch; virginia.kukula@gmail.com
}

Received 30 August 2017; Accepted 23 October 2017; Published 25 December 2017

Academic Editor: Antony C. Calokerinos

Copyright ( 2017 Wirginia Kukula-Koch. This is an open access article distributed under the Creative Commons Attribution License, which permits unrestricted use, distribution, and reproduction in any medium, provided the original work is properly cited.

\begin{abstract}
Twenty-five methanol extracts obtained from various representatives of Papaveraceae and Berberidaceae botanical families (genera: Papaver, Argemone, Eschscholzia, Chelidonium, Glaucium, and Berberis) were screened for their alkaloid content in an optimized method suitable for the LC-ESI-Q-TOF-MS analysis. Twelve pharmacologically important isoquinoline alkaloids from four groups, aporphines, benzylisoquinolines, protoberberines, and benzophenanthridines, present in these traditionally used plant species were quantitatively determined in each studied sample, providing their alkaloid profile. A Zorbax Stable Bond RP- 18 column and a mobile phase composed of $0.1 \%$ formic acid and $0.1 \%$ formic acid in acetonitrile (v/v) were used at the flow rate of $0.2 \mathrm{~mL} / \mathrm{min}$. A profound study on the optimization of MS response to four groups of isoquinoline alkaloids (validation of capillary voltage, gas flows, nebulizer pressure, skimmer, and fragmentor voltages), repeatability of results, and stability and linearity of measurements were described, showing, among others, $3000 \mathrm{~V}$ of capillary voltage, $350^{\circ} \mathrm{C}$ of gas temperature, $12 \mathrm{~L} / \mathrm{min}$ of gas flows, nebulizer pressure of $35 \mathrm{psig}$, $65 \mathrm{~V}$ for skimmer voltage, and $30 \mathrm{~V}$ for collision energy as the most advantageous operation parameters.
\end{abstract}

\section{Introduction}

Isoquinoline alkaloids (ISQAs)—nitrogen containing secondary metabolites derived from the two amino acids phenylalanine and tyrosine-are the largest group of natural products. They are known from their prominent pharmacological activities and vast applications in modern pharmacotherapeutical strategies as single compounds or in pharmaceutical preparations from the whole plants [1]. Among ISQAs, morphine (an opioid analgesic drug) [2], berberine (a digestive system stimulant and antiprotozoal, antinociceptive, and neuroprotective agent) [3], boldine (a bile production stimulant), codeine (analgesic and antitussive remedy) [4], galanthamine (a competitive reversible acetylcholinesterase inhibitor used in mild and moderate dementia) [5], or papaverine (antispasmotic agent) should be listed as commonly used medicines [2].

Even if ISQAs comprise a variety of chemical structures with different levels of oxygenation, additional rings, and substituents, their basic skeleton always contains an isoquinoline moiety or a tetrahydroisoquinoline ring [4].
ISQAs may be divided into eight subgroups, four of which were evaluated in the presented study: protoberberines (which account for $25 \%$ of all ISQAs), aporphines, benzophenanthridines, and benzylisoquinolines $[4,6]$. Described alkaloids are widespread in nature, although their highest content can be found in plants, in various representatives of Berberidaceae, Papaveraceae, Ranunculaceae, Rutaceae, Fumariaceae, or Menispermaceae [1, 6]. Due to significant pharmacological importance of these alkaloids, a thorough validation of mass spectrometry conditions in their analysis, directly in plant extracts, is presented in this manuscript. It is worth to note that still some of them are obtained from natural sources, which encourages the authors to discuss on their determination in the extracts and later on the purification by various separation techniques [4].

Based on the well-established applications in traditional medicine and a variety of ISQAs confirmed in their extracts, several Berberidaceae and Papaveraceae representatives have been selected for the purpose of this study. The importance and use of plant species belonging to the genus Papaver has a very long history dating back some 3,000 years, when it was 
already administered in the form of opium (containing a complex of alkaloids) as a pain-relieving remedy. Besides, various species of poppies have been used in the treatment of upper respiratory tract diseases, cough, and hoarseness and to facilitate the expulsion of mucus [7]. Barberry species are commonly administered bile production inducers. These widespread shrubs also exhibit antipyretic, anti-inflammatory, antidiarrheal, and hepatoprotective properties [8] and are present in a variety of traditional formulations and in homeopathy.

Even if these plants have been used for ages in traditional pharmacotherapeutical strategies, still multiple studies on their novel pharmacological applications are conducted, revealing new possible applications of their constituents, such as neuroprotective or anticancer activities $[5,8]$.

In the light of these findings, there is a strong need for the development of new, more accurate, specific, and precise analytical methods for their characterization. Electrospray (ESI) mass spectrometry is a sensitive analytical tool, which enables the determination of single compounds in a complex matrix. It was found to deliver high-accuracy data, which provided a successful identification of isoquinolines of different kind [9-11]. The aim of this manuscript is to carefully design the operation parameters of a high-resolution mass spectrometer, LC-ESI-Q-TOF-MS, such as fragmentation energies, gas flows and temperatures, skimmer voltage, and nebulizer pressure, to deliver high-accuracy qualitative and quantitative data for the determination of ISQAs in plant materials. The analyses will be performed on four model alkaloids-the representatives of different subgroups of ISQAs to indicate their analytical behaviour. Because of a high popularity and a marked sensitivity of this particular type of mass spectrometer, the optimization results may be applied in various plant species from the abovementioned botanical families.

Additionally, the determination of some selected alkaloids under the optimized analytical conditions will be performed on 25 extracts obtained from poppy and barberry species to create their chemotaxonomical fingerprint and fish the most valuable ones-the most rich in alkaloids.

\section{Materials and Methods}

2.1. Reagents. Acetonitrile, water, and formic acid of spectroscopic purity were obtained from J. T. Baker (Center Valley, PA, USA), whereas the extraction solvents were obtained from Avantor Performance Materials (Gliwice, Poland). $0.45 \mu \mathrm{m}$ nylon syringe filters (Merck, Darmstadt, Germany) were used for the filtration of the obtained extracts at given concentrations. Reference compounds were purchased from ChromaDex Inc. (Irvine, CA, USA).

2.2. Plant Material. Various species of Berberidaceae and Papaveraceae (Table 1) were cut (aerial parts after the flowering, underground parts in the late September before the frost), dried at $40^{\circ} \mathrm{C}$ after collection, finely powdered, and frozen prior to the study. A sample of each plant was stored by the author under voucher specimen numbers WKK2016M001-WKK2016M025.
TABle 1: A list of studied samples.

\begin{tabular}{|c|c|c|c|}
\hline $\begin{array}{l}\text { Extract } \\
\text { number }\end{array}$ & Species name & $\begin{array}{l}\text { Plant } \\
\text { organ }\end{array}$ & $\begin{array}{c}\text { Year } \\
\text { of coll. }\end{array}$ \\
\hline 1 & Chelidonium majus & Herba & 2013 \\
\hline 2 & Argemone ochroleuca & Herba & 2013 \\
\hline 3 & Papaver pseudo-orientale & Folium & 2015 \\
\hline 4 & Papaver caucasicum & Herba & 2013 \\
\hline 5 & Papaver nudicaule & Herba & 2013 \\
\hline 6 & Papaver crocetum & Herba & 2014 \\
\hline 7 & Papaver bracteatum "Arya" & Folium & 2015 \\
\hline 8 & Argemone mexicana & Herba & 2013 \\
\hline 9 & Papaver pillosum & Folium & 2012 \\
\hline 10 & Papaver argemone & Herba & 2011 \\
\hline 11 & Papaver rhoeas & Herba & 2012 \\
\hline 12 & Eschscholzia californica & Herba & 2012 \\
\hline 13 & Papaver orientale & Folium & 2012 \\
\hline 14 & Papaver lapponicum & Herba & 2012 \\
\hline 15 & Glaucium flavum & Herba & 2012 \\
\hline 16 & Berberis siberica & Herba & 2015 \\
\hline 17 & Argemone grandiflora & Herba & 2008 \\
\hline 18 & Berberis cretica & Herba & 2015 \\
\hline 19 & Papaver pseudo-orientale & Radix & 2015 \\
\hline 20 & Eschscholzia californica & Radix & 2014 \\
\hline 21 & Argemone mexicana & Radix & 2011 \\
\hline 22 & Chelidonium majus & Radix & 2009 \\
\hline 23 & Argemone grandiflora & Radix & 2011 \\
\hline 24 & Berberis cretica & Radix & 2015 \\
\hline 25 & Berberis vulgaris & Radix & 2015 \\
\hline
\end{tabular}

All poppies were cultivated in the garden of the Department of Pharmacognosy, Medical University of Lublin. The seeds were obtained from botanical gardens around the world, which the Department of Pharmacognosy collaborates with, for many years now. The plants were additionally authenticated by the author. The root of Berberis vulgaris was purchased in a local herbal shop in Lublin, Poland. The overground parts of Berberis siberica were obtained from Mongolia (from the area of Ulaanbaatar in September 2015) and were authenticated by Dr. Otgonbataar Urjin. Berberis cretica came from Crete island in Greece (the surroundings of Iraklion in September 2015) and was authenticated by the author. The list of species used in the study is given in Table 1.

2.3. Extraction. $1 \mathrm{~g}$ of powdered plant material was extracted by accelerated solvent extraction (ASE) in the apparatus produced by Dionex (ASE 100, Sunnyvale, CA, US) locked in a $10 \mathrm{~mL}$ stainless steel vessel, under the following conditions: extractant: methanol; temperature: $80^{\circ} \mathrm{C}$; static time: $5 \mathrm{~min}$; number of cycles: 1; flush volume: $50 \%$; purge time: $50 \mathrm{~s}$. Pressure was maintained at ca 110 bar. The extraction for each plant species was performed 3 times. The obtained extracts were diluted to the volume of $20 \mathrm{~mL}$, and $1.5 \mathrm{~mL}$ of each was transferred to an HPLC vial through a nylon syringe filter and 
subjected to LC-MS analysis. The remaining samples were dried under vacuum in $50^{\circ} \mathrm{C}$ until dryness.

2.4. Qualitative and Quantitative High-Resolution Mass Spectrometry Analysis of the Extracts. An LC-ESI-Q-TOFMS apparatus produced by Agilent Technologies (Santa Clara, CA, US) was applied in the study. The instrument was composed of an HPLC chromatograph (1260 Series) containing a degasser (G1322A), a binary pump (G1312C), an autosampler (G1329B), a column oven (G1316A), a PDA detector (G1315D), and a mass spectrometer (G6530B) with a quadrupole and a time-of-flight analyzers.

To obtain high-resolution spectra of alkaloids, positive ionisation mode was applied. A gradient of acetonitrile $(B)$ and water $(A)$, both with an addition of formic acid, was carefully adjusted to provide sufficient separation of the extract on a chromatographic column (Zorbax Stable Bond RP-18 Column: $150 \mathrm{~mm} \times 2.1 \mathrm{~mm}, \mathrm{dp}=3.5 \mu \mathrm{m}): 0 \mathrm{~min}-1 \% B$ in $A, 10 \mathrm{~min}-40 \% B$ in $A, 12 \mathrm{~min}-40 \% B$ in $A, 17 \mathrm{~min}-95 \% B$ in $A, 20 \mathrm{~min}-1 \% B$ in $A$, stop time: $30 \mathrm{~min}$. $0.2 \mathrm{~mL} / \mathrm{min}$ flow rate, $5 \mathrm{~min}$ post time, $10 \mu \mathrm{L}$ injection volume, and the $\mathrm{m} / \mathrm{z}$ range from 40 to 1000 were set in the method details. The analysis was performed at $25^{\circ} \mathrm{C}$ [10] on a freshly calibrated apparatus. Two most intensive signals were simultaneously fragmented in the MS/MS analysis. After the collection of 1 spectrum, they were excluded for $0.3 \mathrm{~min}$ from the analysis to collect more fragmentation data from other less intense signals. A calibration mixture was dosed simultaneously during the analysis as an internal standard to sustain high accuracy of the measurements.

To provide the quantitative analysis of alkaloids, four reference compounds-representatives of each class of studied alkaloids-were evaluated: berberine (a protoberberine alkaloid), berbamine (a benzylisoquinoline alkaloid), sanguinarine (a benzophenanthridine type), and magnoflorine (an aporphine alkaloid). All of them were obtained from Chromadex (Irvine, CA, US) at a purity higher than $95 \%$. The calibration curve equations and $R^{2}$ values were calculated for each reference compound from 6 separate injections of different concentrations at the same injection volume.

The MS parameters' optimization study was performed on the most diverse extract, methanol extract from Berberis siberica, based on the three separate injections for each changed parameter. Majority of the MS parameter settings were validated: capillary voltage varied from 3000 to $4000 \mathrm{~V}$, fragmentor energy from 75 to 175 , gas temperatures from $300^{\circ} \mathrm{C}$ to $400^{\circ} \mathrm{C}$, drying gas flows from 10 to $12 \mathrm{~L} / \mathrm{min}$, nebulizer from 25 to $40 \mathrm{psig}$, skimmer from 40 to $70 \mathrm{~V}$, and collision energies from 10 to $80 \mathrm{~V}$ (Table 2).

The following factors were included in the validation of the best evaluated method: the limit of detection (LOD) expressed as signal-to-noise $(\mathrm{S} / \mathrm{N})$ times 3 (measured in the vicinity of the peak of interest), the limit of quantification (LOQ) calculated as $\mathrm{S} / \mathrm{N}$ times 10 [12], linearity (linear range determination), and precision deviation (interday and intraday variations) determined for $n=5$ peak area measurements recorded once on the same day and another time
TABle 2: The influence of spectrometric parameters on the determination of the studied four representatives of isoquinoline alkaloids, expressed in the peak area of the compounds in relation to the highest one in each group (in percent). The most optimum settings for all groups of alkaloids are in italics.

\begin{tabular}{|c|c|c|c|c|c|}
\hline Instrument sett & ings & $\% \mathrm{BBR}$ & $\% \mathrm{BBM}$ & $\% \mathrm{MGN}$ & $\% \mathrm{SNG}$ \\
\hline & A3000 & 100.00 & 54.88 & 100.00 & 100.00 \\
\hline & A 3250 & 98.77 & 66.97 & 92.28 & 96.25 \\
\hline & $A 3500$ & 97.19 & 96.48 & 90.23 & 95.17 \\
\hline & A 3750 & 82.83 & 100.00 & 81.28 & 84.77 \\
\hline & A4000 & 82.80 & 99.93 & 77.76 & 81.96 \\
\hline & 75 & 52.21 & 62.47 & 55.49 & 58.39 \\
\hline & 100 & 70.36 & 64.59 & 76.28 & 66.37 \\
\hline & 125 & 85.44 & 69.81 & 95.08 & 87.35 \\
\hline & 150 & 98.46 & 95.72 & 99.95 & 99.02 \\
\hline & 175 & 100.00 & 100.00 & 100.00 & 100.00 \\
\hline & 300 & 99.96 & 99.94 & 100.00 & 98.91 \\
\hline Gas & 325 & 100.00 & 100.00 & 99.90 & 100.00 \\
\hline temperatures & 350 & 99.37 & 99.62 & 99.92 & 99.36 \\
\hline$\left({ }^{\circ} \mathrm{C}\right)$ & $\begin{array}{l}350 \text { and } 375 \\
\text { (sheath gas) }\end{array}$ & 97.77 & 80.09 & 99.87 & 95.44 \\
\hline Drying gas and & 10 and 10 & 95.65 & 92.98 & 95.09 & 96.12 \\
\hline sheath gas & 11 and 11 & 97.55 & 97.39 & 99.77 & 98.30 \\
\hline flow: & 12 and 12 & 100.00 & 100.00 & 100.00 & 100.00 \\
\hline & 25 & 63.44 & 77.86 & 52.95 & 66.18 \\
\hline Nebulizer & 30 & 75.22 & 86.90 & 64.45 & 78.22 \\
\hline pressure (psig) & 35 & 100.00 & 100.00 & 98.57 & 100.00 \\
\hline & 40 & 99.34 & 99.55 & 100.00 & 99.90 \\
\hline & 40 & 45.18 & 47.42 & 47.96 & 43.03 \\
\hline & 50 & 86.51 & 60.99 & 93.69 & 81.45 \\
\hline Sk1n & 60 & 99.38 & 100.00 & 95.25 & 97.76 \\
\hline voltage (V) & 65 & 100.00 & 98.69 & 100.00 & 100.00 \\
\hline & 70 & 92.17 & 50.10 & 97.32 & 98.33 \\
\hline
\end{tabular}

at the very end of the sequence after 48 hours from the first injection (Table 3).

MassHunter B.07.00 software enabled both the conduction of analyses and the management of the obtained spectral data.

\section{Discussion}

3.1. The Validation of LC-ESI-Q-TOF-MS Operation Parameters. The aim of the study was to show the behaviour of four model representatives of different subgroups of isoquinoline alkaloids: BBR, which belongs to protoberberines; SNG, a benzophenanthridine alkaloid; MGN, an aporphine alkaloid; and BBM, a benzylisoquinoline alkaloid, in various conditions of mass spectrometric analysis. Unlike the commonly described optimization parameters, like stability, repeatability, or precision deviation assessment for the performed tests, the evaluation of general mass spectrometer settings is more rare in the scientific literature. Often, universal MS settings characteristic for each analytical laboratory are applied also for the determination of various secondary metabolites, including alkaloids, giving less accurate MS measurements. The author's intention was to present the influence of different operating parameters like temperature, pressure, and voltage on the abundance of alkaloids of interest 
TABLE 3: Method validation parameters for the studied model alkaloids: linearity, precision, limits of detection, and quantification.

\begin{tabular}{|c|c|c|c|c|c|c|c|}
\hline Compound & $\begin{array}{c}\text { Regression } \\
\text { equation }\end{array}$ & $R^{2}$ & $\begin{array}{c}\text { Linearity range } \\
(\mu \mathrm{g} / \mathrm{mL})\end{array}$ & $\begin{array}{c}\mathrm{LOD} \\
(\mathrm{ng} / \mathrm{mL})\end{array}$ & $\begin{array}{c}\mathrm{LOQ} \\
(\mathrm{ng} / \mathrm{mL})\end{array}$ & $\begin{array}{c}\text { Intraday precision } \\
\quad(n=5)[\%]\end{array}$ & $\begin{array}{c}\text { Interday precision } \\
(n=5)[\%]\end{array}$ \\
\hline Berberine & $\begin{aligned} y= & 363158032093 x \\
& +856955661\end{aligned}$ & 0.998 & $0.1-100$ & 47 & 157 & 2.6 & 3.1 \\
\hline Berbamine & $\begin{array}{c}y=55985070215 x \\
+4453198619\end{array}$ & 0.997 & $0.1-250$ & 25 & 84 & 3.4 & 4.2 \\
\hline Magnoflorine & $\begin{array}{c}y=35358955125 x \\
+9667117613\end{array}$ & 0.998 & $0.1-100$ & 18 & 61 & 1.8 & 2.1 \\
\hline Sanguinarine & $\begin{aligned} y= & 7879756395 x \\
& +48208329\end{aligned}$ & 0.997 & $0.1-100$ & 22 & 73 & 1.2 & 1.4 \\
\hline
\end{tabular}

in the analyzed extracts. Table 2 shows the percentage differences between the peak areas of 4 alkaloids determined in the Siberian barberry herb methanolic extract, in different spectrometric conditions applied. For this purpose, the highest peak area of each group was assigned as $100 \%$ intensity, and the others were calculated in relation to the former. The deviations in the peak area measurements were observed on a spectrum of this complex matrix of $B$. siberica extract to provide standard analysis conditions, which differ greatly from those of single reference compounds' injections. As it is presented in Table 2, the majority of selected parameters determine the final response of the instrument dependent on the sample ionisation efficiency.

Except from capillary voltage, all determined parameters were found to affect the injected extract in a similar way. The study revealed that berbamine-a representative of benzylisoquinoline alkaloids-delivered a better abundance in the higher capillary voltage. This behaviour might be explained by its dimeric structure, higher molecular weight, and stronger energy needed to transform the molecule into an ion. The other tested alkaloids showed an opposite reaction. To well center the applied conditions, the energy of $3500 \mathrm{~V}$ was selected as the most promising and supporting the highest abundances of all groups of compounds. In the case of three remaining compounds (BBR, SNG, and MGN), the decrease of capillary voltage below $3000 \mathrm{~V}$ did not bring better results.

Also, other MS instrument parameters influenced the quantification of the sample markedly. According to the results presented in Table 2, the fragmentor voltage was important for the generation of ions from the injected matrix. The lower its voltage, the smaller the quantity of ions detected by the analyzer. On the other hand, high voltage, such as $175 \mathrm{~V}$ at the instrument entrance, even if providing the highest peak areas, led to a faster fragmentation of alkaloids already in source, resulting in more crowded MS spectra. Considering the above, $150 \mathrm{~V}$ energy was used in the following analyses.

Surprisingly, the parameters of the carrier gases did not play any major role in the determination of these alkaloids. The temperature of gas and sheath gas, tested in the range of $300-375^{\circ}$, similarly to their flows (from 10 to $12 \mathrm{~L} / \mathrm{min}$ ) induced only minor, insignificant deviations.

On the other hand, the nebulizer pressure and the skimmer voltage were found to influence the analysis greatly.
As much as an average 35\% drop in the peak areas of all alkaloids was calculated for the pressure of 25 psig in relation to 35 psig. Aporphines were found to be the most sensitive for the change of this parameter. The application of 35 and 40 psig resulted in the highest response of the apparatus. The peak area of berbamine was the most resistant to the applied energies.

Skimmer voltage of 60 and $65 \mathrm{~V}$ was found to be the most beneficial, contrary to $40 \mathrm{~V}$, which occurred to be a boarder setting, above which, a significant rise in the operation sensitivity was observed.

The last parameter to be optimized was the CID energy corresponding to the formation of the MS/MS spectra. A range of collision energies from 10 to $80 \mathrm{~V}$ was tested in the search for good fragmentation of these alkaloids. The results showed noticeable differences between the spectra depending on the CID energy applied. A sufficient fragmentation pattern for these alkaloids was obtained already in $30 \mathrm{~V}$, still providing the presence of a molecular peak.

Lower energy values showed very weak fragmentation, when the highest used, crashed the structure into very small fragments making the identification troublesome. The list of obtained fragments for all tested energies is presented in Table 4.

Considering the above observations, the following analytical method including the best conditions for the alkaloid determination was composed: capillary voltage $3500 \mathrm{~V}$, fragmentor energy from $\mathrm{v} 150$, gas temperatures from $350^{\circ} \mathrm{C}$, drying gas flows from $12 \mathrm{~L} / \mathrm{min}$, nebulizer from $35 \mathrm{psig}$, skimmer from $65 \mathrm{~V}$, and collision energies CID from 20 to $30 \mathrm{~V}$. Even if all described conditions are close to one another, the validated method parameters would certainly provide better results.

Some scientific papers show the determination of isoquinoline alkaloids in the samples of a different origin, like human plasma, molluscs, or different TCM preparations containing a variety of plant extracts. In a study of Yuan et al. [13], the determination of alkaloids was performed in both positive and negative ionisation modes in the capillary voltage of $3000 \mathrm{~V}$, drying gas temperature of $325^{\circ} \mathrm{C}$, and nebulizing gas pressure of 350 set for the study of yanhusuo herb. Shi et al. [14] applied $3000 \mathrm{~V}$ of capillary voltage, collision energy of $35 \mathrm{~V}$, and the fragmentation energy of $6 \mathrm{~V}$ in a study on the rat plasma constituents. Also Zhou et al. [15] used an LC-MS apparatus for the determination of 
TABLE 4: The behaviour of model alkaloids in different collision energies together with the abundance of obtained signals.

\begin{tabular}{|c|c|c|c|c|}
\hline Number & Alkaloid & Precursor ion & & $\begin{array}{l}\text { agments obtained at various CID voltage (V) } \\
\text { h abundances in different intensities (\%) }\end{array}$ \\
\hline \multirow{7}{*}{ (1) } & \multirow{7}{*}{ Berberine } & \multirow{7}{*}{336} & $10 \mathrm{~V}$ & $336(100), 337(27), 321(5)$ \\
\hline & & & $20 \mathrm{~V}$ & $336(100), 321(43), 292(22)$ \\
\hline & & & $30 \mathrm{~V}$ & $320(100), 292(73), 321(69), 306(26)$ \\
\hline & & & $40 \mathrm{~V}$ & 320 (100), 278 (55), 292 (49), 318 (31), 306 (25) \\
\hline & & & $50 \mathrm{~V}$ & $278(100), 318(38), 292(31), 279$ (2) \\
\hline & & & $60 \mathrm{~V}$ & $278(100), 263(31), 249(27), 220(26)$ \\
\hline & & & $80 \mathrm{~V}$ & $191(100), 220(47), 204(46), 192(38)$ \\
\hline \multirow{7}{*}{$(2)$} & \multirow{7}{*}{ Magnoflorine } & \multirow{7}{*}{342} & $10 \mathrm{~V}$ & $342(100), 343$ (31), 297 (12), 58 (10) \\
\hline & & & $20 \mathrm{~V}$ & 297 (100), 265 (85), $342(78), 58(71)$ \\
\hline & & & $30 \mathrm{~V}$ & $58(100), 265(29), 297(16)$ \\
\hline & & & $40 \mathrm{~V}$ & $58(100), 191(31), 222(29)$ \\
\hline & & & $50 \mathrm{~V}$ & $58(100), 179$ (20), $192(10)$ \\
\hline & & & $60 \mathrm{~V}$ & $58(100), 165(56), 176(20)$ \\
\hline & & & $80 \mathrm{~V}$ & $58(100), 165(50), 178(40)$ \\
\hline \multirow{7}{*}{ (3) } & \multirow{7}{*}{ Sanguinarine } & \multirow{7}{*}{332} & $10 \mathrm{~V}$ & $332(100), 333(27), 334(3)$ \\
\hline & & & $20 \mathrm{~V}$ & $332(100), 333(24), 304(7)$ \\
\hline & & & $30 \mathrm{~V}$ & $332(100), 274(41), 304(39), 317$ (34) \\
\hline & & & $40 \mathrm{~V}$ & $274(100), 304(60), 246(52), 216(30)$ \\
\hline & & & $50 \mathrm{~V}$ & 304 (100), 216 (55), $246(48), 189(22)$ \\
\hline & & & $60 \mathrm{~V}$ & $246(100), 216(60), 260(40), 189(30)$ \\
\hline & & & $80 \mathrm{~V}$ & $189(100), 202(85), 176(75)$ \\
\hline \multirow{7}{*}{ (4) } & \multirow{7}{*}{ Berbamine } & \multirow{7}{*}{609} & $10 \mathrm{~V}$ & 609 (100), 610 (38), $611(35), 612(16)$ \\
\hline & & & $20 \mathrm{~V}$ & $609(100), 611(76), 206(29), 579(12)$ \\
\hline & & & $30 \mathrm{~V}$ & 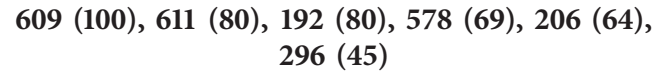 \\
\hline & & & $40 \mathrm{~V}$ & 206 (100), 192 (93), $174(36), 190(34), 296$ (34) \\
\hline & & & $50 \mathrm{~V}$ & 206 (100), 192 (90), 296 (52), 239 (41) \\
\hline & & & $60 \mathrm{~V}$ & 206 (100), 192 (62), $174(47), 296(40)$ \\
\hline & & & $80 \mathrm{~V}$ & $160(100), 191(94), 165(85), 174(84)$ \\
\hline
\end{tabular}

Note: the most optimal parameters are given in bold.

isoquinolines. In their research on the Lotus nelumbo compounds, the scientists applied $3000 \mathrm{~V}$ on a capillary and the temperature at $300^{\circ} \mathrm{C}$ to identify the constituents characterized by an anti-inflammatory action. In the light of the above discussed optimization, the previously published parameters, even if correct, seem not to use the maximum accuracy of the spectrometers.

3.2. Method Validation. The LOD and LOQ values were calculated for each alkaloid by a series of sample dilutions injected at the volume of $10 \mu \mathrm{L}$ under the optimized parameters. The former was calculated as $\mathrm{S} / \mathrm{N} 3: 1$, the latter as $\mathrm{S} / \mathrm{N}$ of $10: 1$ according to Saadati et al. [12].

All measured values of LODs were far below the linearity ranges for matching alkaloids as indicated in Table 3 and varied between 18 and $47 \mathrm{ng} / \mathrm{mL}$. The measured LOQs stayed within the range of $61-157 \mathrm{ng} / \mathrm{mL}$. All drawn calibration curves of reference compounds were found to have a good linearity with correlation coefficient values higher than 0.997. In the optimized method, the response of apparatus to small concentrations of alkaloids was high so that the linearity range is within $0.1-250 \mu \mathrm{g} / \mathrm{mL}$, similarly to those determined on other apparatus [10]. The deviation of results obtained in the interday and intraday precision measurements of all alkaloids were below 5\%, which confirms high stability of the method.
3.3. Determination of Alkaloids in the Selected Extracts of Papaveraceae and Berberidaceae Representatives. 25 obtained extracts from selected Papaveraceae (genera: Papaver, Eschscholzia, Chelidonium, Argemone, and Glaucium) and Berberidaceae species (Berberis spp.) were evaluated for their qualitative and quantitative composition in the optimized method. According to the scientific literature, the following alkaloids from 4 groups of ISQAs were expected to occur in the analyzed samples: BBR, JTR, STP, SNG, CHE, ARM, BBM, OBB, and CHD (Figures 1 and 2) [16, 17]. All of them were identified, using the validated method, as separate peaks, in accordance with the scientific literature, their fragmentation patterns, Metlin database, and the behaviour of reference compounds. All compounds were quantified using the formerly described calibration curves (Table 3) of four model alkaloids. The data are presented in Table 3.

The listed compounds have been selected due to their significant pharmacological activities and a growing interest in their purification and activity assessment, to introduce the studied plant species as potential sources for their purification. Berberine, as the most widespread compound, has been already thoroughly studied. However, the remaining compounds still demand more attention and precise phytochemical profile assessment.

BBR was detected in all plant species from Papaveraceae and Berberidaceae and may be treated as a chemotaxonomic 


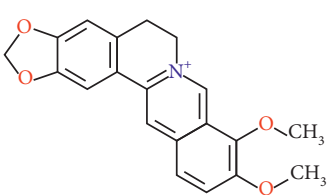

Berberine

$\mathrm{C}_{20} \mathrm{H}_{18} \mathrm{NO}_{4}{ }^{+}$

$\mathrm{MW}=336$<smiles>CN1Cc2c(ccc3c2OCO3)[C@@H]2[C@@H](O)Cc3cc4c(cc3[C@H]21)OCO4</smiles>

Chelidonine

$\mathrm{C}_{20} \mathrm{H}_{19} \mathrm{NO}_{5}$

$\mathrm{MW}=353$<smiles>COc1cc2c(cc1OC)C(Cc1ccc(O)cc1)N(C)CC2</smiles>

Armepavine

$\mathrm{C}_{19} \mathrm{H}_{23} \mathrm{NO}_{3}$

$\mathrm{MW}=313$<smiles>COc1cc2c(cc1OC)-c1cc3ccc(OC)c(OC)c3c[n+]1CC2</smiles>

Palmatine

$\mathrm{C}_{21} \mathrm{H}_{22} \mathrm{NO}_{4}{ }^{+}$

$\mathrm{MW}=352$<smiles>COc1cc2c(cc1O)CC[n+]1cc3c(OC)c(OC)ccc3cc1-2</smiles>

Jatrorrhizine

$\mathrm{C}_{20} \mathrm{H}_{20} \mathrm{NO}_{4}^{+}$

$\mathrm{MW}=338$

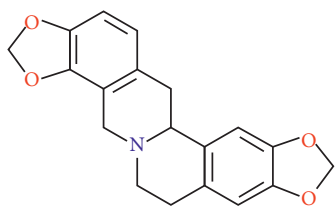

Stylopine

$\mathrm{C}_{19} \mathrm{H}_{17} \mathrm{NO}_{4}$

$\mathrm{MW}=323$<smiles>COc1ccc2c(c[n+](C)c3c4cc5c(cc4ccc23)OCO5)c1OC</smiles>

Chelerythrine

$\mathrm{C}_{20} \mathrm{H}_{14} \mathrm{NO}_{4}{ }^{+}$

$\mathrm{MW}=348$<smiles></smiles>

Obaberine

$\mathrm{C}_{38} \mathrm{H}_{42} \mathrm{~N}_{2} \mathrm{O}_{6}$

$\mathrm{MW}=622$<smiles>COc1ccc2c(c1O)-c1c(O)c(OC)cc3c1[C@@H](C2)[N+](C)(C)CC3</smiles>

Magnoflorine
$\mathrm{C}_{20} \mathrm{H}_{24} \mathrm{NO}_{4}^{+}$
$\mathrm{MW}=342$<smiles>C[n+]1cc2c3c(ccc2c2ccc4cc5c(cc4c21)OCO5)OCO3</smiles>

Sanguinarine $\mathrm{C}_{20} \mathrm{H}_{14} \mathrm{NO}_{4}{ }^{+}$ $\mathrm{MW}=332$<smiles></smiles>

Berbamine $\mathrm{C}_{37} \mathrm{H}_{40} \mathrm{~N}_{2} \mathrm{O}_{6}$ $\mathrm{MW}=608$<smiles>COc1cc2c(cc1O)[C@H](Cc1ccc(O)cc1)N(C)CC2</smiles>

N-Methylcoclaurine
$\mathrm{C}_{18} \mathrm{H}_{21} \mathrm{NO}_{3}$ $\mathrm{MW}=299$

Figure 1: The chemical structures of the quantified isoquinoline alkaloids with their molecular weights and chemical formulas.

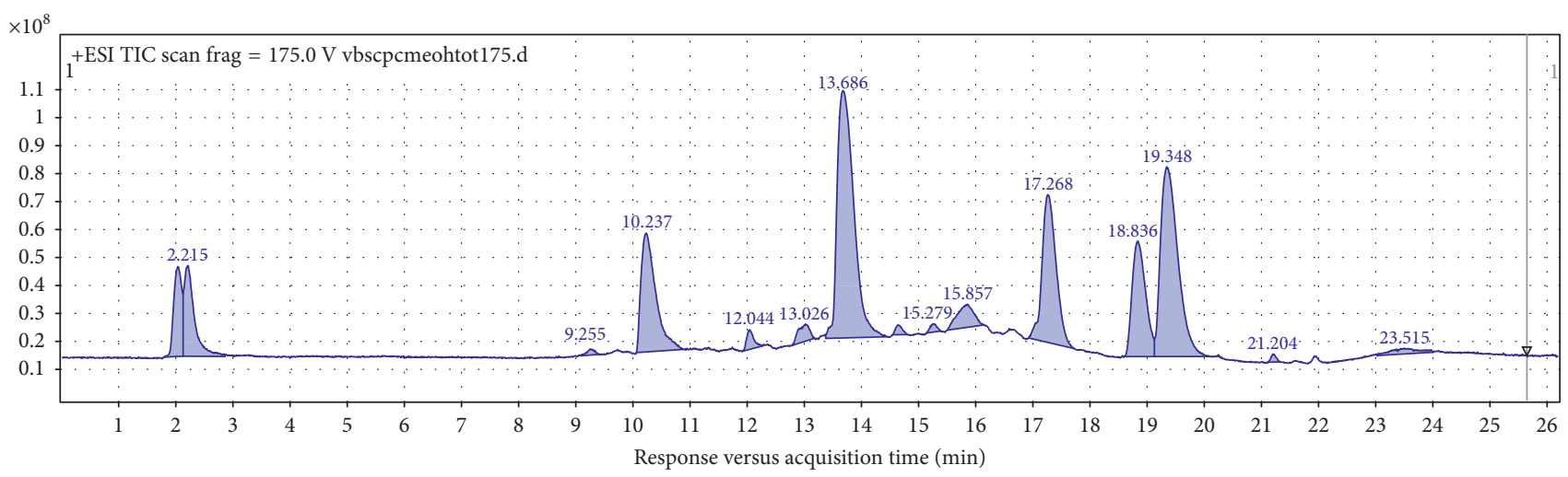

FIGURE 2: TIC of a sample extract: Berberis cretica methanol root extract in the optimized LC-MS method with BBR at 19.3 min, PLM at $18.8 \mathrm{~min}, \mathrm{JTR}$ at $17.2 \mathrm{~min}, \mathrm{OBB}$ at $16.6 \mathrm{~min}, \mathrm{STP}$ at $15.8 \mathrm{~min}, \mathrm{BBM}$ at $15.2 \mathrm{~min}, \mathrm{ARM}$ at $14.6 \mathrm{~min}$, and $\mathrm{MGN}$ at $13.7 \mathrm{~min}$.

marker of these families. As described by Jensen and Kadereit [18], this alkaloid is present in all Ranunculiflorae-in Berberidaceae, Fumariaceae, Menispermaceae, Papaveraceae, and Ranunculalceae representatives. The extracts from barberry species did not reveal any presence of SNG, CHE, or CHD contrary to the poppies.

$\mathrm{BBM}$ and $\mathrm{OBB}$ were more abundant in barberry species, especially in their underground parts, whereas aporphines were spread more equally between the representatives of two families. PLT accompanied BBR in majority of extracts, whereas STP was present more often in the studied barberry species. Root samples contained higher concentrations of the produced alkaloids; however, still a higher diversity of compounds was noted in the green parts of the plants. Berberis root extracts belonged to the least diverse ones, but the quantities of identified alkaloids in their samples were 


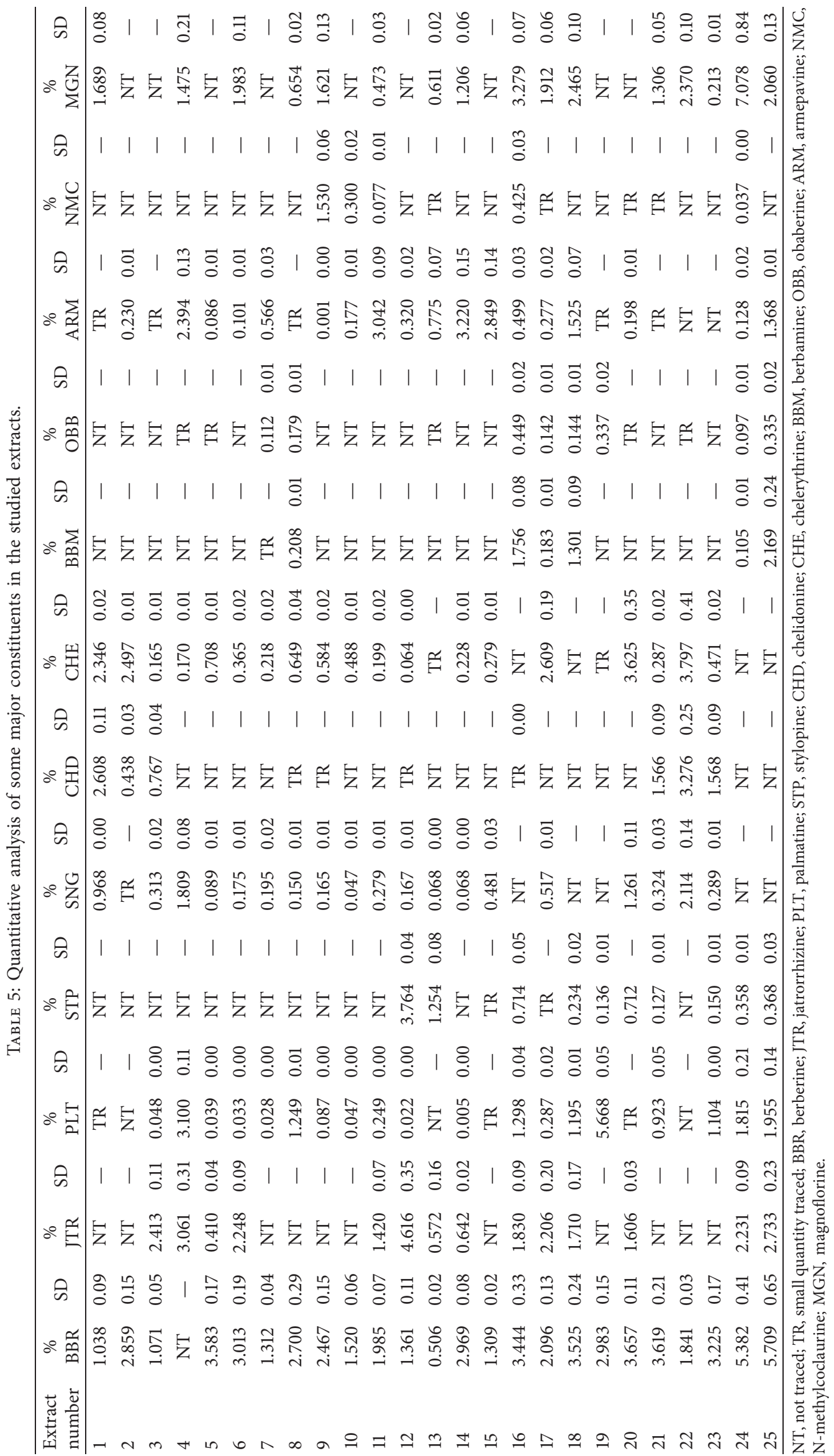


high. Berberis cretica contained the highest quantity of MGN ( 7\%) (Figure 2), and Berberis vulgaris contained the highest quantity of BBR ( $5.7 \%)$. Papaver nudicaule was the most rich in BBR among the poppies, Eschscholzia californica contained the highest amount (4.6\%) of JTR and STP (3.7\%) in the herb, and Papaver pseudo-orientale was characterized by a high content of PLT (5.7\%)-the highest among all tested extracts. Poppies were found to contain two out of three quantified benzophenanthridine alkaloids: SNG ( $P$. caucasicum with the highest content) and CHE (Argemone grandiflora herb). The least abundant compound among all tested extracts was $\mathrm{N}$-methylcoclaurine-an aporphine found in P. pillosum in the highest concentration of $1.5 \%$ (Table 5 ).

\section{Conclusions}

The evaluated LC-ESI-Q-TOF-MS methodology led to a successful determination of 12 pharmacologically important isoquinoline alkaloids in 25 methanolic extracts from Papaveraceae and Berberidaceae representatives, with high accuracy, stability, and repeatability of results. The quantitative analysis of selected alkaloids in many plant extracts indicated new potential sources for the isolation of these pharmacologically valuable molecules.

\section{Abbreviations}

ARM: Armepavine

BBM: Berbamine

BBR: Berberine

CHD: Chelidonine

CHE: Chelerythrine

CID: Collision-induced dissociation

ISQA: Isoquinoline alkaloids

JTR: Jatrorrhizine

MGN: Magnoflorine

MS: $\quad$ Mass spectrometry

NMC: N-Methylcoclaurine

OBB: Obaberine

PLT: Palmatine

STP: Stylopine

TIC: Total ion current.

\section{Conflicts of Interest}

The author declares that there are no conflicts of interest regarding the publication of this paper.

\section{Acknowledgments}

The author was supported by The National Center for Research and Development, Poland, project number 4/POLTUR-1/2016.

\section{References}

[1] L. Grycová, J. Dostál, and R. Marek, "Quaternary protoberberine alkaloids," Phytochemistry, vol. 68, no. 2, pp. 150-175, 2007.
[2] T. Trang, R. Al-Hasani, D. Salvemini, M. W. Salter, H. Gutstein, and C. M. Cahill, "Pain and poppies: the good, the bad, and the ugly of opioid analgesics," Journal of Neuroscience, vol. 35, no. 41, pp. 13879-13888, 2015.

[3] W. Kukula-Koch, W. Koch, A. Angelis, M. Halabalaki, and N. Aligiannis, "Application of $\mathrm{pH}$-zone refining hydrostatic countercurrent chromatography (hCCC) for the recovery of antioxidant phenolics and the isolation of alkaloids from Siberian barberry herb," Food Chemistry, vol. 203, pp. 394-401, 2016.

[4] W. Kukuła-Koch and J. Widelski, "Alkaloids," in Pharmacognosy: Fundamentals, Applications and Strategy, pp. 163-198, Academic Press, 2017.

[5] W. Kukula-Koch and T. Mroczek, "Application of hydrostatic CCC-TLC-HPLC-ESI-TOF-MS for the bioguided fractionation of anticholinesterase alkaloids from Argemone mexicana L. roots," Analytical and Bioanalytical Chemistry, vol. 407, no. 9, pp. 2581-2589, 2015.

[6] E. V. Leitao Da-Cunha, I. M. Fechine, D. N. Guedes, J. M. Barbosa-Filho, and M. S. da Silva, "Protoberberine alkaloids," in The Alkaloids, G. A. Cordell Ed., vol. 62, pp. 1-75, Academic Press, New York, London, 2005.

[7] G. B. Stefano, N. Pilonis, R. Ptacek, and R. M. Kream, "Reciprocal evolution of opiate science from medical and cultural perspectives," Medical Science Monitor, vol. 23, pp. 2890-2896, 2017.

[8] N. Mokhber-Dezfuli, S. Saeidnia, A. Gohari, and M. KurepazMahmoodabadi, "Phytochemistry and pharmacology of Berberis species," Pharmacognosy Reviews, vol. 8, no. 15, pp. 8-15, 2014.

[9] J. Liu, H. Wu, F. Zheng et al., "Simultaneous determination of the content of isoquinoline alkaloids in Dicranostigma leptopodum (Maxim) Fedde and the effective fractionation of the alkaloids by high-performance liquid chromatography with diode array detection," Journal of Separation Science, vol. 38, no. 1, pp. 9-17, 2014.

[10] A. Singh, V. Bajpaj, S. Kumar, K. Ram Arya, K. Rai Sharma, and B. Kumar, "Quantitative determination of isoquinoline alkaloids and chlorogenic acid in Berberis species using ultra high performance liquid chromatography with hybrid triple quadrupole linear ion trap mass spectrometry," Journal of Separation Science, vol. 38, no. 12, pp. 2007-2013, 2015.

[11] W. N. Wu and L. A. McKown, "The in vitro metabolism of thalicarpine, an aporphine-benzyltetrahydroisoquinoline alkaloid, in the rat. API-MS/MS identification of thalicarpine and metabolites," Journal of Pharmaceutical and Biomedical Analysis, vol. 30, no. 1, pp. 141-150, 2002.

[12] N. Saadati, M. P. Abdullah, Z. Zakaria, S. B. T. Sany, M. Rezayi, and H. Hassonizadeh, "Limit of detection and limit of quantification development procedures for organochlorine pesticides analysis in water and sediment matrices," Chemistry Central Journal, vol. 7, no. 1, p. 63, 2013.

[13] L. Yuan, J. Yin, M. Tian et al., "The classification and identification of complex chemical compositions in yanhusuo herb using UPLC-Q-TOF/MS," Analytical Methods, vol. 8, no. 10, pp. 2274-2281, 2016.

[14] T. Shi, Z. Yao, Z. Qin, B. Ding, Y. Dai, and X. Yao, "Identification of absorbed constituents and metabolites in rat plasma after oral administration of Shen-Song-Yang-Xin using ultra-performance liquid chromatography combined with quadrupole time-of-flight mass spectrometry," Biomedical Chromatography, vol. 29, no. 9, pp. 1440-1452, 2015. 
[15] M. Zhou, M. Jiang, X. Ying et al., "Identification and comparison of anti-inflammatory ingredients from different organs of Lotus nelumbo by UPLC/Q-TOF and PCA coupled with a NF-kB reporter gene assay," PLoS ONE, vol. 8, no. 11, article e81971, 2013.

[16] R. Istatkova, S. Philipov, and P. Tuleva, "Alkaloids from Mongolian species Berberis sibirica Pall," Comptes Rendus de L'Academie Bulgare des Sciences, vol. 60, no. 11, pp. 11771182, 2007.

[17] J. Schmidt, C. Boettcher, C. Kuhnt, T. M. Kutchan, and M. H. Zenk, "Poppy alkaloid profiling by electrospray tandem mass spectrometry and electrospray FT-ICR mass spectrometry after [ring-13C6]-tyramine feeding," Phytochemistry, vol. 68, no. 2, pp. 189-202, 2007.

[18] U. Jensen and J. W. Kadereit, Systematics and Evolution of the Ranunculiflorae, Springer-Verlag, Wien, Austria, 1995. 

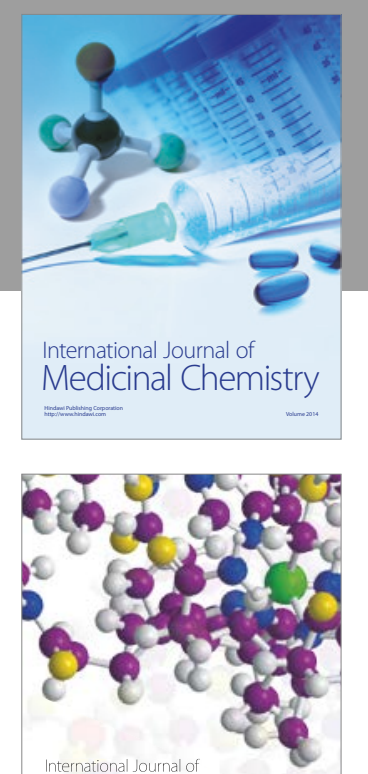

Carbohydrate Chemistry

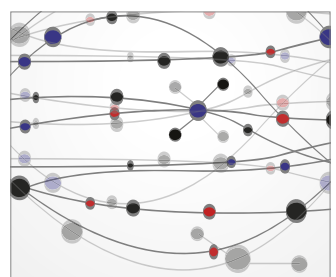

The Scientific World Journal
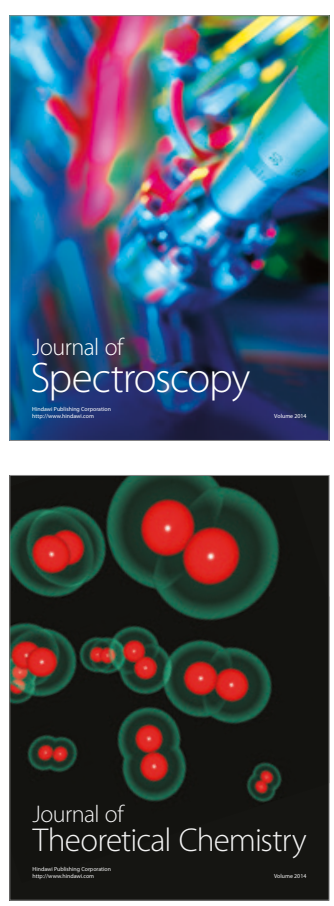
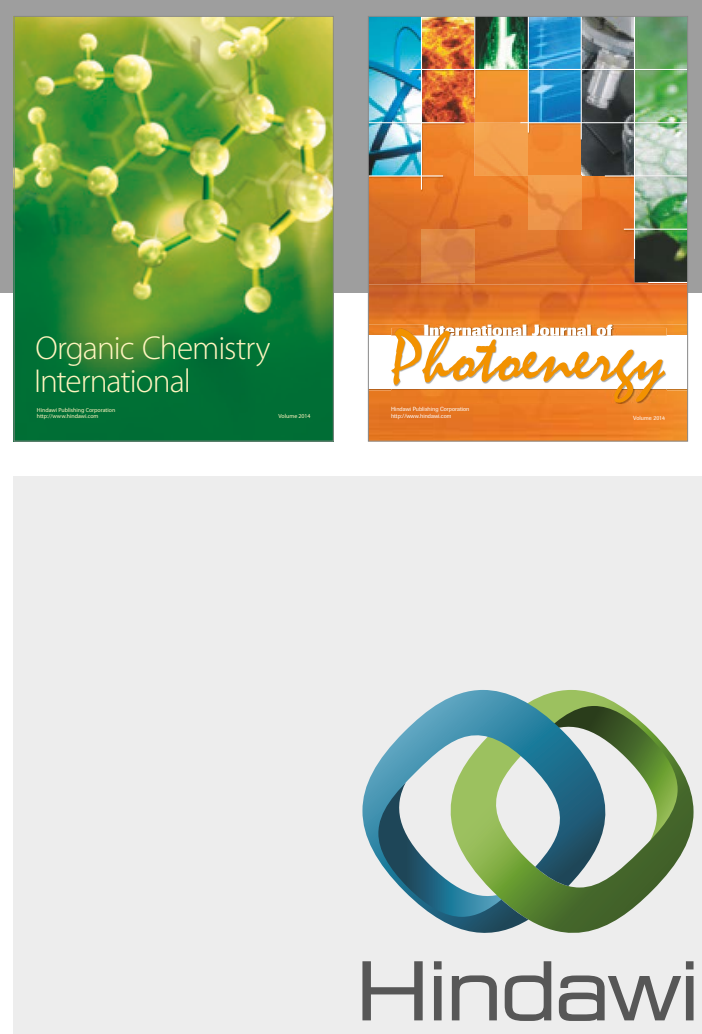

Submit your manuscripts at

https://www.hindawi.com

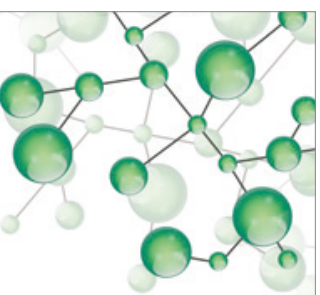

International Journal of

Inorganic Chemistry

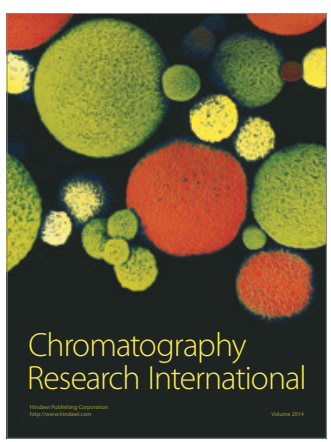

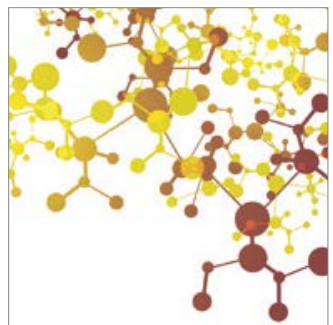

Applied Chemistry
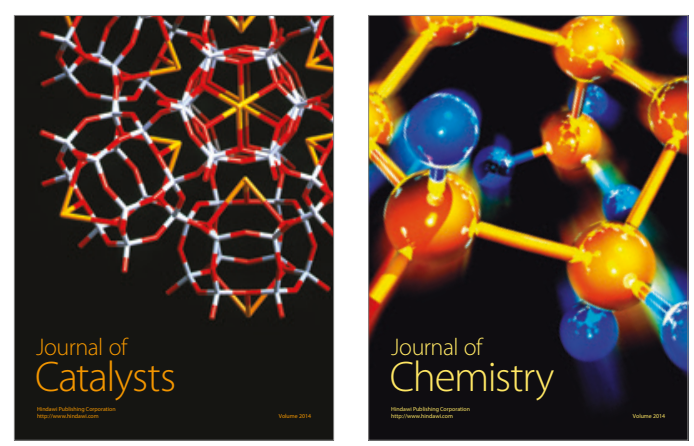
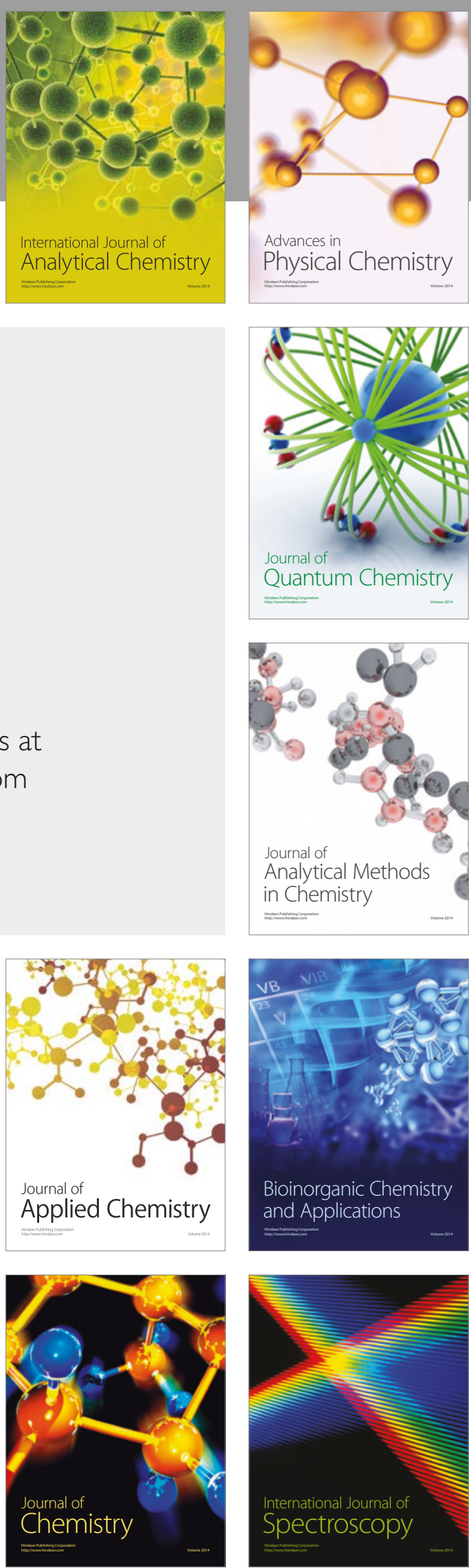